\title{
Replication of Herpes Simplex Virus in Blood Monocytes and Placental Macrophages from Human Neonates
}

\author{
SUSAN PLAEGER-MARSHALL, BONNIE J. ANK, KARL M. ALTENBURGER, LEWIS I. PIZER, \\ RICHARD B. JOHNSTON, JR., AND E. RICHARD STIEHM \\ Department of Pediatrics, UCLA School of Medicine, Los Angeles, California $90024-1747$ [S.P-M., B.J.A., \\ E.R.S.]; Department of Pediatrics, University of Pennsylvania School of Medicine, and The Children's Hospital \\ of Philadelphia, Philadelphia, Pennsylvania, 19104 [R.B.J.]; and Departments of Pediatrics and Microbiology, \\ University of Colorado School of Medicine, Denver, Colorado 80262 [K.M.A., L.I.P.]
}

\begin{abstract}
Increased permissiveness of macrophages for herpes simplex virus (HSV) replication may be a mechanism for the dissemination and severity of neonatal herpetic infection. We have assessed the replication of HSV in neonatal blood monocytes and placental macrophages using several criteria for viral permissiveness. Assay of production of infectious progeny virus indicated that cord blood monocytes, like adult monocytes, were nonpermissive for HSV (about $1 \%$ of cells producing virus). In vitro culture of cord blood monocytes resulted in increased replication of $\mathrm{HSV}$, but to no greater extent than virus production in cultured adult cells. HSV infection of fetal placental macrophages was weak but present $(4.4 \%$ of cells). Assay of production of viral antigens and electron microscopic analysis of structural elements indicated that a larger number of cord blood monocytes and placental macrophages were abortively infected than were productively infected. These results indicate that monocytes and macrophages from human neonates do not show the enhanced permissiveness for HSV demonstrated in newborn mice and suggest that dissemination of herpetic infection in human newborns cannot be explained by increased neonatal monocyte permissiveness for HSV. (Pediatr Res 26: 135-139, 1989)
\end{abstract}

\section{Abbreviations}

HSV (1 or 2), herpes simplex virus (type 1 or 2 )

CBM, cord blood monocytes

PM, placental macrophages

MNC, mononuclear cells

MEM, minimal essential medium, Eagle's

HBSS, Hanks buffered saline solution

MOI, multiplicity of infection

PFU, plaque forming units

TCA, trichloroacetic acid

Neonates are particularly susceptible to disseminated disease following perinatal exposure to HSV (1). In the murine model, the enhanced susceptibility of newborn animals to HSV infection has been linked to the increased permissiveness of immature

Received January 24, 1989; accepted March 29, 1989

Correspondence and reprint requests Dr. Susan Plaeger-Marshall, Department of Pediatrics UCLA School of Medicine, Los Angeles, CA 90024.

Supported by Grants HD 09800, AI 24782, and AI 17873 from the United States Public Health Service. macrophages for HSV replication $(2,3)$. Although early experiments provided indirect evidence for a similar mechanism for the dissemination of human neonatal herpetic infection $(4,5)$, definitive studies characterizing the replication of HSV in mononuclear phagocytes from human newborns have yet to be performed. We have assessed the replication of HSV in neonatal blood monocytes and placental macrophages using several criteria for viral permissiveness. The results indicate that monocytes from newborns are nonpermissive for HSV, as are monocytes from adults, with virus in the majority of the infected cells undergoing abortive replication. Fetal tissue macrophages from placenta, which are more differentiated than monocytes, showed limited productive replication of HSV. These data indicate that mononuclear phagocytes from human neonates do not show the high degree of permissiveness for HSV that has been demonstrated in murine neonatal herpetic infection.

\section{MATERIALS AND METHODS}

Virus. Macintyre strain (ATCC no. VR-539 [American Type Culture Collection (ATCC), Rockville, MD]) was propagated in a standard manner in HEp-2 cells (ATCC no. CCL 23) using low-multiplicity infection (6). HSV-2 strain 186 (kindly provided by Dr. Priscilla Schaeffer, Harvard University, Boston, MA) was similarly passaged in rabbit skin cells. Cell lines were carried in Eagle's MEM supplemented with 5\% FCS, glutamine (2 mM), penicillin $(100 \mathrm{U} / \mathrm{mL})$, and streptomycin $(1000 \mathrm{~g} / \mathrm{ml})$. Virus stocks were titered by standard plaque quantitation in Vero cells (6) and stored at $-70^{\circ} \mathrm{C}$ until use.

Peripheral blood monocyte isolation. Cord blood was obtained from normal term deliveries and anticoagulated with acid-citratedextrose or heparin. In most experiments, the blood was processed within $1 \mathrm{~h}$; in some experiments, there was up to a 6-h delay. No difference was found in the results using cells processed immediately or after $6 \mathrm{~h}$. MNC were obtained by standard density gradient centrifugation (7) over Lymphoprep (Nyegaard, Oslo, Norway) or, in some experiments, by a modification of a previously published procedure (8) using a BSA gradient. In the latter procedure, red blood cells were removed by sedimentation over $3 \%$ dextran, and the leukocytes were suspended in BSA at a density of $1.1 \mathrm{~g} / \mathrm{mL}$. The cell suspension was overlayed with BSA at a density of $1.05 \mathrm{~g} / \mathrm{mL}$, and the gradients were centrifuged at $10000 \times g$ for $30 \mathrm{~min}$. MNC were collected at the interface.

Monocytes were isolated from MNC by adherence to plastic tissue culture dishes for $2 \mathrm{~h}$ at $37^{\circ} \mathrm{C}$ in $5 \% \mathrm{CO}_{2}$ in RPMI 1640 medium supplemented with $10 \%$ FCS, antibiotics, and glutamine as described above. Nonadherent cells were removed from the plates by repeated washing with HBSS, and the adherent 
monocytes incubated in RPMI containing 5-10\% human $A B$ serum or autologous serum. Monocytes were assayed within 24 $\mathrm{h}$ of isolation, or were allowed to remain in culture for 4-7 days, during which time the cells differentiated into macrophages (9).

Placental macrophage isolation. Placental macrophages were isolated using a modification of the method of Uren and Boyle (10). Briefly, the chorionic villi were dissected from placentas obtained within $5 \mathrm{~h}$ after normal, uncomplicated delivery. After washing with sterile normal saline to remove as much contaminating blood as possible, the villi were minced with sterile scissors. The minced tissue was then sequentially digested at room temperature in a solution of trypsin $(0.25 \%)$ and DNAse $(0.1$ $\mathrm{mg} / \mathrm{ml}$; Sigma Chemical Co., St. Louis, MO, no. D0876) in HBSS without calcium and magnesium. The first digestion was carried out for $60 \mathrm{~min}$, and this digest, which contained mostly peripheral blood cells, was discarded. Three subsequent digestions, using fresh solution for each, were carried out for $30 \mathrm{~min}$ each. Digests were collected into $10 \%$ FCS, washed, and suspended in RPMI 1640 medium with $10 \%$ FCS. Cells were held on ice until all digestions were completed. The three digests were pooled, the cells washed two times in HBSS, and centrifuged over a Lymphoprep density gradient. Macrophages were further separated by adherence for 1-2 h to plastic tissue culture dishes. Nonadherent cells were removed by washing, and the cells were incubated overnight in RPMI with $10 \%$ FCS. For assays, macrophages were removed by Versene buffer treatment (11) and/ or scraping with a rubber policeman. Cells were $>95 \%$ macrophages, as determined by morphology and nonspecific esterase staining, and viability by trypan blue exclusion was $>98 \%$.

Viral replication assays. Cells were plated in 24-well plates $\left(16-\mathrm{mm}\right.$ wells) at $5 \times 10^{5}$ cells in $1.0 \mathrm{~mL}$ RPMI and allowed to adhere for $2 \mathrm{~h}$ at $37^{\circ} \mathrm{C}$ in $5 \% \mathrm{CO}_{2}$. Supernatant medium was removed and $0.1 \mathrm{~mL}$ of virus inoculum added to each well, for a MOI of $10 \mathrm{PFU}$ of HSV per cell. Virus was allowed to adsorb for $2 \mathrm{~h}$ at $37^{\circ} \mathrm{C}$. Unadsorbed virus was removed by washing three times with HBSS to avoid masking of new virus progeny by residual inoculum. To obtain the 2 -h sampling, duplicate wells were harvested by scraping with a plastic pipette tip and collecting suspended cells and medium. Plates with the remaining wells were incubated at $37^{\circ} \mathrm{C}$ in $5 \% \mathrm{CO}_{2}$, and duplicate wells were similarly harvested at 24,48 , and $72 \mathrm{~h}$ postinfection. Samples were stored at $-70^{\circ} \mathrm{C}$ until assay of virus titer. Titers of HSV in the samples were determined by plaque quantitation on Vero cell monolayers. Cells permissive for HSV (Vero or HEp-2) and treated identically to the monocytic cells served as controls. HSV added to wells without cells indicated the rate of thermal extinction of the virus.

Infectious center assay. Cells were infected at an MOI $=10$ for $2 \mathrm{~h}$. Unadsorbed virus was removed by washing three times with HBSS and followed by treatment with a 1:10 dilution of rabbit polyclonal antibody to HSV-1 Macintyre (Dako Corporation, Santa Barbara, $C A$, neutralization titer of $1: 1024)$, which had been dialyzed to remove azide, or rabbit antiserum to HSV2186 (neutralization titer of $1: 128$ ). Cells were removed using Versene buffer (11), counted, and serial 10-fold dilutions of cells were plated in duplicate onto susceptible Vero cell monolayers. Plates were overlaid with $1 \%$ methylcellulose in standard medium and incubated for 3 days at $37^{\circ} \mathrm{C}$ in $5 \% \mathrm{CO}_{2}$. Plates were fixed in $4 \%$ formalin and stained with a $0.5 \%$ solution of crystal violet. Plaques were counted and the number of cells producing infectious progeny virus calculated per $5 \times 10^{4}$ cells plated or as percent of total cells. Permissive control cells were either Vero or HEp-2 cells treated in the same manner as the monocytes.

Immunofluorescence. Monocytes were infected at an MOI = 100 and incubated at $37^{\circ} \mathrm{C}$ for $24 \mathrm{~h}$. Cells were removed using Versene buffer, washed with HBSS, and slides were prepared using a cytocentrifuge (Shandon, Inc., Pittsburgh, PA). Slides were fixed in ice-cold acetone and treated with a 1:10 dilution of goat whole serum (Cappel, West Chester, PA) to block nonspecific binding of antibody by monocyte Fc receptors. Slides were stained with an affinity-purified polyclonal goat antibody to HSV labeled with fluorescein isothiocyanate (catalog no. B1029-50, Bartels Immunodiagnostic Supplies, Bellevue, WA), mounted using buffered glycerol, and viewed using a Leitz Dialux fluorescent microscope. A total of 200 cells was counted to obtain percent cells fluorescing. Positive and negative control slides were provided in a kit with the labeled antibody.

Electron microscopy. Cells were infected with HSV as described above for immunofluorescence. After removal from the plates with Versene, cells were gently pelleted and fixed in $2 \%$ glutaraldehyde in cacodylate buffer. The cell pellets were postfixed in osmium tetroxide, dehydrated in an ethanol series, and embedded in epoxy resin (Medcast, Ted Pella, Inc., Redding, CA). Thin sections were stained with uranyl acetate and lead citrate and examined using a Philips 300 electron microscope (Philips Electronics Instruments, Inc. Garden Grove, CA). At least 20 cells were scanned to obtain percentage of cells containing viral particles.

Measurement of DNA synthesis. Monocytes $\left(1 \times 10^{6}\right)$ were plated in $35-\mathrm{mm}$ tissue culture plates and were infected with $\mathrm{HSV}$ at an $\mathrm{MOI}=100$ either within $24 \mathrm{~h}$ or after culture for 7 days. After a 2-h incubation with virus, cells were washed and $10 \mu \mathrm{Ci}$ of $\left[{ }^{3} \mathrm{H}\right] \mathrm{TdR}$ in standard medium added to each plate. Cells were incubated at $37^{\circ} \mathrm{C}$ in $5 \% \mathrm{CO}_{2}$ for 4,8 , or $12 \mathrm{~h}$. At these testing times, duplicate plates were placed on ice and immediately washed with cold PBS. Ice cold $10 \%$ TCA was added, and the plate was incubated on ice for $10 \mathrm{~min}$. The TCA was removed and replaced with an additional 1-2 $\mathrm{mL}$ of cold TCA, and the plates were incubated on ice for an additional 5 min. The cells were washed two more times with TCA, once with $95 \%$ ethanol, and inverted until dry. When the plates were dry, $0.5 \mathrm{~mL}$ of $15 \mathrm{~N}$ ammonium hydroxide was added, and the cells were scraped from the plates. Duplicate aliquots of $0.2 \mathrm{~mL}$ were removed for counting of $\beta$-emission in a liquid scintillation counter.

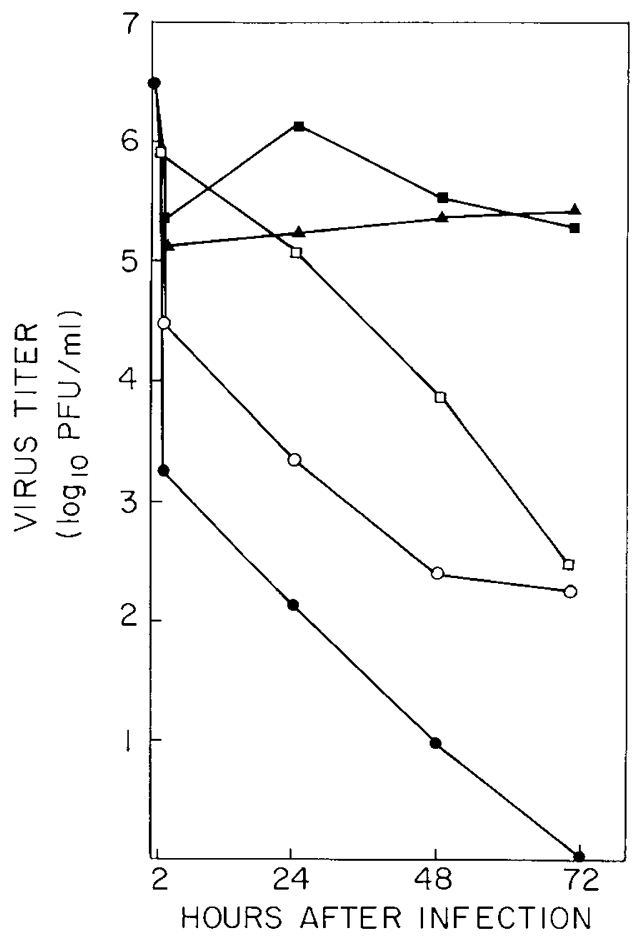

Fig. 1. Production of infectious progeny virus over time. The $0-h$ point represents the initial virus inoculum. Unadsorbed inoculum was removed after a 2-h incubation and before harvesting of cells for the 2-h test point. Blood monocytes from adults $(\bullet)$ or cords $(O)$, placental macrophages $(\mathbf{A})$, permissive cell controls $(\mathbf{Q})$, thermal inactivation controls $(\square)$. 


\section{RESULTS}

Viral replication curves. Exposure of adult or cord blood monocytes to HSV within $24 \mathrm{~h}$ of cell isolation resulted in decreasing titers of virus over the 72-h assay period, indicating no infectious progeny were produced by these cells. The means of results from three adult and five cord blood samples using HSV-1 are shown in Figure 1. Replication curves using HSV-2 were similar; a limited number of experiments assaying earlier $(8 \mathrm{~h}$ postinfection) or later ( $96 \mathrm{~h}$ postinfection) time-points revealed no early or late bursts in virus production for either HSV-1 or 2, with these points following the general downward trend in virus titer (data not shown). HSV titers increased in the permissive control cultures, whereas thermal extinction controls showed inactivation of virus at $37^{\circ} \mathrm{C}$ in the absence of cells. The mean of results from five placentas showed no decline in viral titers over time, indicating that fetal tissue macrophages were able to replicate HSV to a limited extent (Fig. 1). Because of the large SD resulting from the variability in the amount of virus produced by the individual monocyte and macrophage samples, there was no significant difference in the titers of virus produced by monocytes versus PM except at the $72 \mathrm{~h}$ time point (SD bars not shown on Fig. 1 for clarity).

Infectious center assays. To determine if a small number of cord or adult monocytes producing HSV were being masked by a predominantly nonpermissive cell population, infectious centers were determined. As shown in Table 1, and average of $85 \%$ of control cells in six experiments produced infectious progeny, whereas less than $1.5 \%$ of either the cord or adult monocytes did. Placental macrophages showed a mean of $5.5 \%$ infectious centers in four experiments, indicating that, in agreement with the virus titer assay, more tissue macrophages were able to support the productive replication of HSV.

Infectious centers were also assayed after infection with HSV1 or 2 of monocytes that had been cultured from 4-7 days in vitro to induce their differentiation into macrophages (9). Results for two cord and two adult samples with HSV-2 are shown in Figure 2. The permissiveness of cord monocytes for either type HSV increased after culture, as did that of adult cells. However, there was no proportional increase in infectious centers in neonatal compared to adult cells, and, in some cases, adult monocytes produced statistically greater numbers of infectious centers than did cord cells (Fig. 2) $(p=0.01)$.

Immunofluorescence. Results of the immunofluorescence studies indicated that a larger number of cells produced viral antigen than were able to replicate infectious progeny (Table 1). Approximately four times the number of cord or adult monocytes or placental macrophages expressed detectable HSV antigen than gave rise to infectious centers. Cord and adult monocytes showed equivalent results. Control cells expressed an average of $92 \%$ antigen-positive cells.

Electron microscopy. Transmission electron microscopy showed that the estimated percentages of cells containing virion structures were similar to those of cells positive for viral antigen by immunofluorescence (placental macrophages $=20 \%$; cord monocytes $=5 \%$ ). However, most of the capsid structures contained electron-lucent cores (Fig. 3), rather than the dense cores characteristic of complete virions. This result suggests defective

Table 1. HSV infection of human monocytes/macrophages

\begin{tabular}{lcc} 
Cell type & $\begin{array}{c}\text { \% cells producing } \\
\text { infectious virus } \\
\text { (infectious centers) }\end{array}$ & $\begin{array}{c}\text { \% cells producing } \\
\text { viral antigen } \\
\text { (immunofluorescence) }\end{array}$ \\
\hline Placental macrophages & $4.4 \pm 2.7^{*}$ & $17 \pm 5^{*}$ \\
Cord monocytes & $1.0 \pm 1.0$ & $4.4 \pm 2.3$ \\
Adult monocytes & $1.3 \pm 1.2$ & $5 \pm 3$ \\
Control (HEp-2) cells & $85 \pm 8$ & $92 \pm 4$ \\
\hline
\end{tabular}

* Mean (SD) for $n=4-6$.

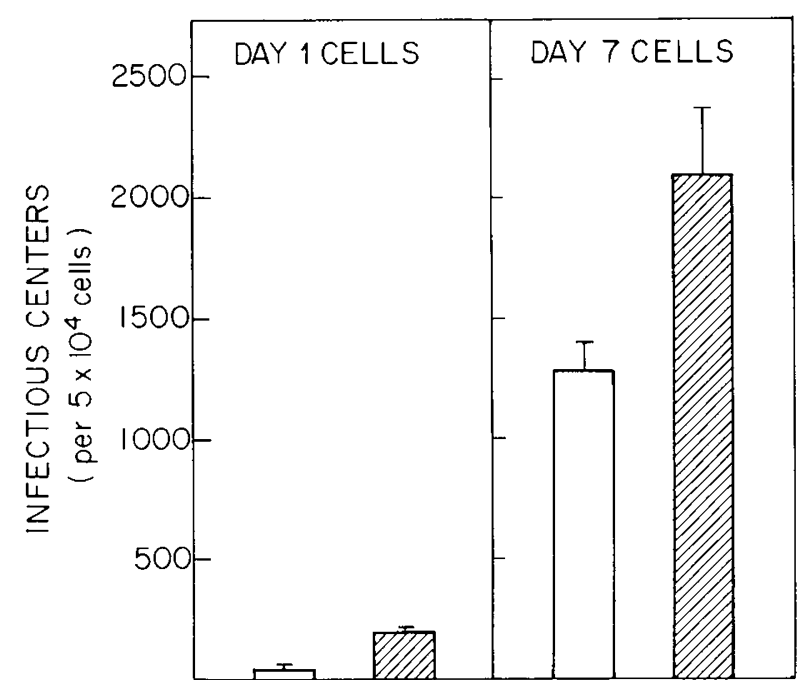

Fig. 2. Number of permissive cells in fresh and cultured blood monocyte populations. Infectious centers were determined for freshly isolated (day 1) or cultured (day 7) monocytes from two cord ( $\square$ ) or two adult (ש्थ) samples. The bars represent 1 SEM determined from $8-10$ replicate plates per sample.

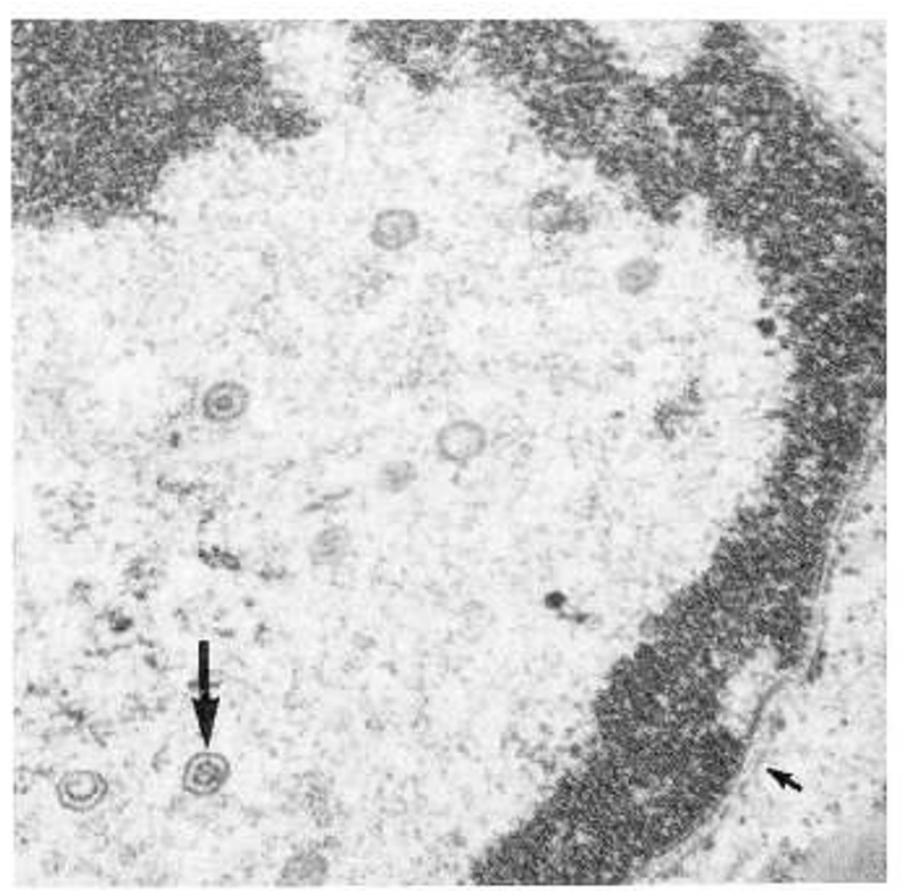

Fig. 3. Incomplete virion structures in a placental macrophage. A transmission electron micrograph shows viral capsids in the nucleus of a placental macrophage at $24 \mathrm{~h}$ postinfection. The majority of the capsids lack dense central cores characteristic of mature, infectious virions (large arrow). The nuclear membrane is indicated by the small arrow; dense, marginated chromatin can be seen just inside the double membrane.

DNA packaging seen in abortive infection, described for adult peripheral blood monocytes (12).

DNA synthesis in infected monocytes. Monocytes do not proliferate in in vitro culture (9), and HSV infection causes a rapid shut-down in cellular DNA synthesis (13). Therefore, the synthesis of viral DNA in infected cells is reflected by increased incorporation of $\left[{ }^{3} \mathrm{H}\right] \mathrm{TdR}$. The results, shown in Figure 4 left, indicated that a small increase in DNA synthesis occurred in cord and adult monocytes exposed to virus $24 \mathrm{~h}$ after cell isolation. Thus, some viral DNA replication occurred in both cell types. 


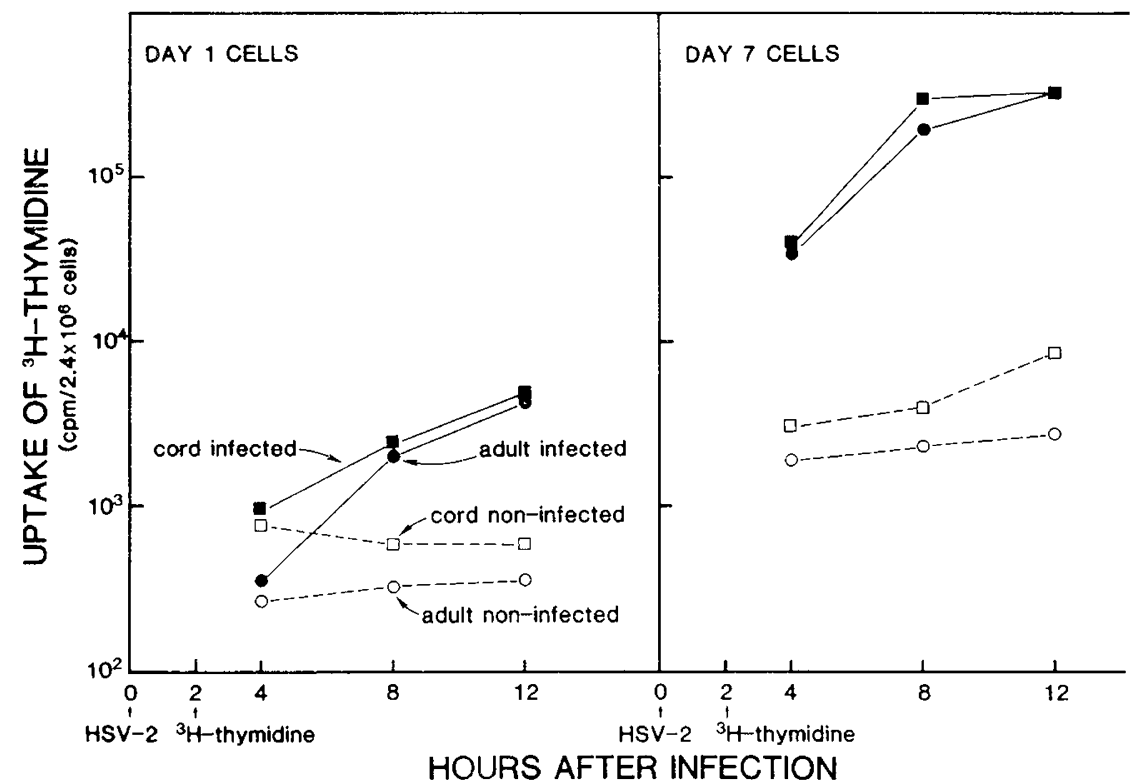

Fig. 4. Replication of viral DNA in infected and uninfected monocytes. Peripheral blood monocytes from adults (circles) or cords (squares) were assayed for DNA replication by $\left[{ }^{3} \mathrm{H}\right] \mathrm{TdR}$ uptake after exposure to HSV (solid lines) or medium only (dotted lines) after culture for 1 or 7 days.

However, there was no difference in the amount of DNA synthesized by adult and neonatal monocytes. Cells that were allowed to differentiate into macrophages in 7-day culture showed substantially more viral replication than the cells infected after $24 \mathrm{~h}$, indicated by increased $\left[{ }^{3} \mathrm{H}\right] \mathrm{TdR}$ incorporation (Figure 4 right). However, macrophages derived from cultured neonatal monocytes showed no greater viral DNA production than did those derived from adult cells.

\section{DISCUSSION}

We (14) and others $(12,15)$ have shown previously that peripheral blood monocytes from healthy adults are not permissive for the productive replication of $\mathrm{HSV}$, but acquire the ability to replicate virus during maturation in vitro. Our study shows similar results using cord blood monocytes, indicating that monocytes from newborns appear no more permissive for the replication of HSV than those from adults. Furthermore, although differentiation of neonatal monocytes in vitro resulted in increased permissiveness for HSV, the increase was actually greater in adults than in neonates. These data suggest that the dissemination of herpetic infection in human newborns cannot be explained by increased neonatal monocyte permissiveness for HSV. The data also indicate that the enhanced permissiveness for HSV of peripheral blood mononuclear leukocytes shown previously (4) reflected viral replication by a cell population other than monocytes. Braun et al. (16) have shown, in fact, that a small fraction of cord blood T cells that appear to be activated in vivo can replicate HSV. Most recently, Hayward et al. (17) have reported that neonatal MNC, either unfractionated or separated into $\mathrm{CD}^{+}(\mathrm{T})$ or HLA-DR ${ }^{+}$(monocyte and $\mathrm{B}$ ) cell fractions were nonpermissive for HSV. However, there was evidence of HSV immediate early protein production, indicating limited viral replication.

In contrast to these findings, Mintz et al. (5) have reported that alveolar macrophages from newborns are more permissive for HSV than are those from adults. This discrepancy may be due to any of several factors. It is of note that the alveolar macrophages used in the study of Mintz et al. (5) were obtained postmortem and, therefore, may not reflect the situation in healthy, viable neonates. Alternately, the difference may be due to the tissue origin, and hence more differentiated state, of alveolar cells compared to cultured blood monocytes. We (18) and others (19) have suggested that the replicative ability of HSV within mononuclear phagocytes is highly dependent upon the state of maturation or differentiation of the cell examined, which may reflect the anatomical source or method of obtaining the cells. Recently, Tenney and Morahan (20) have used the monocytic cell line U937 to show that phorbol ester-induced differentiation of these cells is accompanied by an increase in permissiveness for HSV. Thus, as yet undefined metabolic events that occur during the process of macrophage differentiation appear to be critical in allowing the productive replication of HSV.

Our study also indicates that, compared to monocytes from cord or adult blood, fetal placental macrophages generally had a greater proportion of cells capable of being productively infected. However, this finding may reflect the tissue derivation of placental cells, and their more differentiated state, rather than the fact that neonatal macrophages are more permissive than cells from adults. The limited number of placental cells productively infected (i.e. small numbers of infectious centers) (Table 1) and evidence of more extensive abortive replication indicate a minor degree of permissiveness.

In contrast to these results, the study of Stevens and Cook (3) describing the increased permissiveness of murine neonatal macrophages showed large numbers of infected neonatal cells containing mature virions, whereas adult murine cells showed primarily coreless virions indicative of abortive infection. Study of adult macrophages of a maturation state comparable to fetal placental macrophages will be necessary to determine definitely if fetal tissue macrophages differ from adult tissue cells in their ability to support HSV replication. However, it is of note that the ability of some placental macrophages to replicate virus presents the possibility that the placenta may be a site for HSV replication in vivo under appropriate conditions.

It should also be noted that our study does not precisely duplicate the classic studies done in mice, raising the possibility that the macrophage subpopulations examined may be more or less permissive for HSV. A recent study of Kohl et al. (21) indicates that, in fact, neonatal murine macrophages from the spleen are not permissive for HSV in vitro. The earlier studies performed in neonatal mice examined resident peritoneal macrophages $(2,3)$, a population of cells not easily accessible in human neonates. However, we have used cultured monocytes, 
which approximate the maturational stage of resident peritoneal cells (9), and found no evidence of increased viral permissiveness. In conclusion, these data indicate that mononuclear phagocytes from human newborns do not display the degree of permissiveness for HSV shown by cells from mice (3), and suggest that, in contrast to the murine model, macrophages from human newborns are no more likely to contribute to the spread of herpetic infection than are cells from HSV-infected adults.

Acknowledgments. The authors thank Monica Eiserling of the Jonsson Comprehensive Cancer Center at UCLA for performing the electron microscopy and Marygrace Literatus for manuscript preparation.

\section{REFERENCES}

1. Kohl S 1984 The immune response of the neonate to herpes simplex virus infection. In: Rouse BT, Lopez C (eds) Immunobiology of Herpes Simplex Virus Infection. CRC Press, Boca Raton, FL, pp 121-129

2. Hirsch MS, Zisman B, Allison AC 1970 Macrophages and age-dependent resistance to herpes simplex virus in mice. J Immunol 104:1160-1165

3. Stevens JG, Cook ML 1971 Restriction of herpes simplex virus by macrophages. J Exp Med 133:19-38

4. Trofatter KF, Daniels CA, Williams RJ, Gall SA 1979 Growth of type 2 herpes simplex virus in newborn and adult mononuclear leukocytes. Intervirol 11:117-123

5. Mintz L, Drew WL, Hoo R, Finley TN 1980 Age-dependent resistance of human alveolar macrophages to herpes simplex virus. Infect Immun 28:417420

6. Killington RA, Powell KL 1985 Growth, assay and purification of herpesvirus. In: Mahy BWJ (ed) Virology: A Practical Approach. IRL Press, Oxford, pp 207-236

7. Boyum A 1968 Isolation of mononuclear cells and granulocytes from human blood. Scan J Clin Lab Invest 21(suppl 97):77-89
8. Berman JD Johnson WD 1978 Monocyte function in human neonates. Infect Immun 19:898-902

9. Hammerstrom J 1979 Human macrophage differentiation in vivo and in vitro. Acta Pathol Microbiol Scand [C]87:113-120

10. Uren S, Boyle W 1985 Isolation of macrophages from human placenta. J Immunol Methods 78:25-34

11. Stiehm ER, Sztein MB, Steeg PS, Mann D, Newland C, Blaese M, Oppenheim JJ 1984 Deficient DR antigen expression on human cord blood monocytes: Reversal with lymphokines. Clin Immunol Immunopathol 30:430-436

12. Daniels CA, Kleinerman ES, Snyderman R 1978 Abortive and productive infections of human mononuclear phagocytes by type I herpes simplex virus. Am J Pathol 91:119-129

13. Roizman B, Furlong D 1974 The replication of herpes viruses. In: FraenkelConrat H, Wagner RR (eds) Comprehensive Virology. Plenum Press, New York, pp 229-403

14. Plaeger-Marshall S, Smith JW 1978 Experimental infection of subpopulations of human peripheral blood leukocytes by herpes simplex virus. Proc Soc Exp Biol Med 158:263-268

15. Linnavuori $\mathrm{K}$, Hovi $T 1981$ Herpes simplex virus infection in human monocyte cultures: dose-dependent inhibition of monocyte differentiation resulting in abortive infection. J Gen Virol 52:381-385

16. Braun RW, Teute HK, Kirchner H, Munk K 1984 Replication of herpes simplex virus in human $T$ lymphocytes: Characterization of the viral target cell. J Immunol 132:914-919

17. Hayward A, Laszlo M, Turman M, Vafai A, Tedder D 1988 Non-productive infection of human newborn blood mononuclear cells with herpes simplex virus: effect on T cell activation, IL-2 production and proliferation. Clin Exp Immunol 74:196-200

18. Plaeger-Marshall S, Wilson LA, Smith JW 1980 Permissiveness of rabbit monocytes and macrophages for herpes simplex virus type 1. Infect Immun $35: 151-156$

19. Lopez C, Dudas G 1979 Replication of herpes simplex virus type 1 in macrophages from resistant and susceptible mice. Infect Immun 23:432-437

20. Tenney DJ, Morahan PS 1987 Effects of differentiation of human macrophagelike U937 cells on intrinsic resistance to herpes simplex virus type 1. J Immunol 139:3076-3083

21. Kohl S, Loo LS, Drath DB, Cox P 1989 Interleukin-2 protects neonatal mice from lethal herpes simplex virus infection: a macrophage-mediated, $\gamma$ interferon-induced mechanism. J Infect Dis 159:239-247 